\title{
Consenso para el uso adecuado de antibióticos en el niño menor de 36 meses con fiebre sin foco de infección evidente. Resumen ejecutivo
} Consensus for the proper use of antibiotics in children under 36
months with fever without source of infection. Executive summary

Coordinación: Dra. Miriam Bruno y Dr. Alejandro Ellis ${ }^{a}$ Integrantes: Dr. Fausto M. Ferolla ${ }^{b}$, Dra. Analía De Cristófano y Dra. Anabella Ervitti ${ }^{a}$ Colaboradores: Dr. Fausto Ferolla ${ }^{b}$ Dr. Jorge Celestino ${ }^{b}$, Dra. Graciela Robbio ${ }^{b}$ y Dr. Mario Elmo ${ }^{c}$

http:/ /dx.doi.org/10.5546/aap.2017.205

Véase el texto completo en formato electrónico, en la sección "Consensos" del sitio web de la Sociedad Argentina de Pediatría: www.sap.org.ar

El objetivo del consenso es optimizar el uso de elementos diagnósticos, racionalizar la indicación de antibióticos y minimizar riesgos en la atención de pacientes con potencial infección bacteriana grave (IBG).

La fiebre es un motivo de consulta muy frecuente en pediatría. En aproximadamente $20 \%$ de los casos no encontraremos causa evidente con el examen clínico inicial.

En este resumen señalaremos los aspectos principales a tener en cuenta.

Lo primordial es determinar la causa de la fiebre. La mayoría de niños tendrá un proceso auto limitado de etiología viral. Una pequeña minoría presentará IBG: infección del tracto urinario (ITU), bacteriemia oculta (BO), neumonía, meningitis, gastroenteritis aguda bacteriana, osteomielitis y artritis séptica, entre otras. ${ }^{4}$

A menor edad, mayor es el riesgo de IBG. En los primeros meses de vida hay una inmadurez del sistema inmune y hasta los 2 años la producción de IgM e IgG específica frente a bacterias capsuladas no es adecuada. ${ }^{5}$

Las manifestaciones clínicas, el riesgo de IBG y los microorganismos involucrados varían con la edad y las pautas de atención inicial son diferentes.

La observación y el seguimiento clínico son indispensables para identificar una IBG. Para objetivar este análisis se desarrollaron escalas de observación clínica, entre otras la de la Universidad de Yale (YOS) ${ }^{6}$ y la YIOS (Young infants observation scale). ${ }^{7}$

En general es necesario solicitar estudios complementarios. La proteína
C reactiva y la procalcitonina son los reactantes de fase aguda más considerados. La velocidad de eritrosedimentación tiene baja sensibilidad y especificidad para detectar IBG.

El tratamiento deberá revalorarse a las 48-72 horas y evaluarse, según evolución clínica, cultivos y estudios de laboratorio.

Fiebre sin foco de infección evidente en lactantes menores de 3 meses

En este grupo las escalas de observación clínica aisladas no demostraron ser útiles para detectar IBG en pacientes de este rango etario.

En neonatos, el riesgo de IBG varía entre $12 \%$ y $25 \%$. En aquellos de alto riesgo la prevalencia de IBG llega a 35\%. Los neonatos de bajo riesgo pueden presentar IBG en hasta el 9\% de los casos. En niños de 30 a 90 días la probabilidad es menor; entre 4 y $10 \%$.

En el consenso se señala la identificación de los pacientes con bajo riesgo de desarrollar IBG, con los antecedentes, datos semiológicos y resultados de exámenes complementarios. Existen discrepancias sobre la necesidad de realizar punción lumbar (PL) a los niños de 30 a 90 días con FSF en la evaluación inicial para definir riesgo de IBG, con una prevalencia de meningitis menor a $0,5 \%$.

La ITU es la IBG más frecuente, entre $4 \%$ a $16 \%$ de lactantes 3 meses con FSF. La posibilidad de bacteriemia secundaria en este grupo varía entre 3 a 30\%. Pasada la etapa neonatal, los pacientes con ITU en buen estado general, con o sin bacteriemia, evolucionan favorablemente cuando son tratados con el antibiótico adecuado. 
Se recomienda solicitar radiografía de tórax con recuento de leucocitos mayores a $20.000 / \mathrm{mm}^{3}$, dado el riesgo de neumonía oculta (Nivel de evidencia $I I$ ).

La identificación de infección viral disminuye, pero no descarta la posibilidad de IBG. La IBG más frecuente con infección viral concomitante es la ITU. La coinfección viral-bacteriana se asocia más frecuentemente a fiebre $>39^{\circ} \mathrm{C}$ y leucocitos $>20.000 / \mathrm{mm}^{3}$.

La mayoría de los lactantes con FSF tienen infección viral, las más frecuentes por rotavirus, VSR y enterovirus. Las IBG causadas por E. coli y Streptococcus agalactiae (SGB) son más frecuentes en neonatos. Otros microorganismos involucrados son Klebsiella spp., Enterobacter spp., Neisseria meningitidis (Nm), Hib, Salmonella spp.

En algunos niños se recomienda iniciar un tratamiento antibiótico empírico inicial (TEI), los menores de 1 mes. que habitualmente se internan para ver su evolución y tomar los cultivos y análisis de laboratorio. También deben medicarse todos los pacientes en mal estado general y alto riesgo de IBG por antecedentes o exámenes complementarios anormalesLactantes de 30 a 90 días Los niños de bajo riesgo de IBG y buen estado general se atienden ambulatoriamente, aún sin tratamiento antibiótico: Buen estado general y sin signos de infección.

- Sin antecedentes de importancia: nacido a término, sin complicaciones perinatales, no hospitalizado más tiempo que la madre, sin tratamiento antibiótico previo ni actual, sin internaciones previas, sin enfermedad de base y exámenes normales.

Se deberá realizar 2 hemocultivos y urocultivo. En aquellos lactantes mayores de 2 meses en buen estado general con probable ITU no sería necesario realizar PL y puede indicarse tratamiento ambulatorio, si el seguimiento está asegurado

Los lactantes con alto riesgo de IBG deben internarse y recibir TEI en forma precoz, realizando previamente PL.

\section{¿El TEI tiene algunas diferencias según la edad?}

En neonatos, ampicilina + gentamicina es el recomendado cuando no hay compromiso meníngeo y cefotaxime + ampicilina EV de no poder descartar meningitis.

En lactantes de 30 a 90 días. de alto riesgo, se recomienda ampicilina 200-300 mg/ $\mathrm{kg} /$ día EV cada 6 horas + ceftriaxona $80-100 \mathrm{mg} / \mathrm{kg} /$ día EV cada $12-24$ horas o cefotaxime $150 \mathrm{mg} / \mathrm{kg}$ /día cada 8 horas.

\section{Fiebre sin foco evidente de infección en niños de 3 a 36 meses}

Un niño de 3 meses o más con FSF en buen estado general difícilmente presente enfermedad grave. Para las decisiones será importante verificar el estado de vacunación.

Con el advenimiento de nuevas vacunas y su aplicación masiva, se documentan cada vez menos casos de IBG. Por otra parte, la BO por Hib tiene 12 veces más riesgo de meningitis que por $S p n$. Ante una $\mathrm{BO}$ por este último microorganismo existe 1 a $5,8 \%$ de riesgo de meningitis, 6 a 10\% de otras infecciones localizadas, $0,8 \%$ de letalidad y entre un 70 a $87,5 \%$ puede autolimitarse sin mediar tratamiento. La ITU es la enfermedad febril bacteriana potencialmente grave más frecuente. Está presente hasta el $9 \%$ de estos pacientes, siendo más probable a ante sin foco y con niveles de temperatura superiores a $39^{\circ} \mathrm{C}$.

El riesgo de que un paciente con FSF presente neumonía oculta es de aproximadamente $20 \%$ en niños con fiebre $\geq 39{ }^{\circ} \mathrm{C}$ con leucocitosis $\geq 20000 / \mathrm{mm}^{3}$, por lo que justifica la solicitud de Rx de tórax sólo cuando presenten estas características.

Aún niños correctamente inmunizados tienen cierto riesgo de presentar IBG, especialmente si no tienen bien buen aspecto general. A mayor temperatura, mayor posibilidad de IBG.

\section{¿A qué niños se recomienda iniciar TEI?}

En la era post vacunación neumocócica, existe consenso en no iniciar antibioticoterapia en niños de esta edad con FSF, con buen estado general y análisis urinario normal.

$\mathrm{El}$ paciente que se encuentra en mal estado general (YOS $\geq 10$ ) debe ser internado, realizando hemocultivos, urocultivo, PL, y coprocultivo, este último si presentara diarrea. No se debe demorar el inicio del tratamiento con ceftriaxona a $80-100 \mathrm{mg} / \mathrm{kg} /$ día.

El desafío diagnóstico se encuentra en los niños en buen estado general, sin antecedentes epidemiológicos ni datos clínicos relevantes. Pacientes con FSF de menos de 24 horas de evolución pueden ser observados ambulatoriamente sin realizar estudios complementarios, siempre y cuando sus padres comprendan pautas de alarma y su seguimiento esté asegurado.

En caso de FSF que persiste por más de 24-48 horas, es recomendable realizar análisis urinario y urocultivo. Con sedimento urinario patológico, y de acuerdo al estado clínico, puede iniciarse tratamiento empírico inicial por vía oral (cefalexina $100 \mathrm{mg} / \mathrm{kg} /$ día) en forma ambulatoria, que se adecuará o suspenderá de acuerdo al resultado del urocultivo.

Varias publicaciones avalan el abordaje ambulatorio y sin antibióticos en niños que se encuentran en buen estado general, pero con parámetros de laboratorio de riesgo, siempre y cuando sean posibles controles periódicos minuciosos que incluyan la lectura de los cultivos realizados. El inicio del TEI con ceftriaxona $50 \mathrm{mg} / \mathrm{kg} /$ día es una conducta posible en pacientes pequeños, especialmente los menores de 6 meses, temperatura elevada y falta de cobertura frente a Hib y Spn.

En los últimos 20 años, hubo cambios significativos en la manera de abordar el niño febril 36 meses en base a nuevos elementos diagnósticos, evidencia clínica y modificaciones de la epidemiología, esto último principalmente por la incorporación de la vacuna contra Hib y Spn en los calendarios nacionales. Esto nos obliga a revisar nuestro accionar para tratar de establecer la conducta más precisa, evitando a su vez la utilización innecesaria de antibióticos en pos de la atención de los niños, sujetos de nuestro trabajo diario. 